\title{
Parkinson's disease: disability, review, and management
}

\author{
WILLIAM J MUTCH, ALISON STRUDWICK, SISAR K ROY, ALLAN W DOWNIE
}

\begin{abstract}
Data from a descriptive study of idiopathic Parkinson's disease were analysed aimed at getting a clearer picture of the impact of the disease on the community and the help available to patients and carers. Altogether 267 patients aged $40-92$ were identified, and the median duration of disease in those in whom this could be assessed was $7 \cdot 2$ years.

Of the 267 patients, $204(76.4 \%)$ were living in the community, 51 alone. A total of 201 patients were taking levodopa, 29 out of 102 had retired early, and 60 out of $84(71.4 \%)$ had given up driving. Most patients had symptoms at the time of study, and signs such as bradykinesia, rigidity, impaired speech, and abnormal gait were often moderate or severe. Of 214 patients whose disease was assessed using the scoring system of Hoehn and Yahr, $78(36.4 \%)$ had grade 4 and $23(10.7 \%)$ grade 5 disability. Despite this, however, 105 of 265 patients (39.6\%) were not subject to regular medical review and only 57 of 227 patients $(25 \cdot 1 \%)$ had been seen by an occupational therapist, 16 $(7 \cdot 0 \%)$ by a physiotherapist, and $10(4 \cdot 4 \%)$ by a speech therapist.

Patients with Parkinson's disease may benefit from regular medical review and being seen by therapists.
\end{abstract}

Royal Victoria Hospital, Dundee DD2 1SP

WILLIAM J MUTCH, MCRP, consultant physician in geriatric medicine

Woodend General Hospital, Aberdeen

ALISON STRUDWICK, DIPCOT, occupational therapist

SISAR K ROY, FRCP, consultant physician in geriatric medicine

Department of Medicine, Aberdeen University, Aberdeen

ALLAN $W$ DOWNIE, FRCP, senior lecturer and honorary consultant neurologist

Correspondence to: Dr Mutch.

\section{Introduction}

Parkinson's disease remains a common and disabling condition particularly affecting old people. ${ }^{1}$ In the recent Aberdeen survey we sought to obtain a clearer picture of the impact of the disease on people in the community and what help they receive.

\section{Patients and methods}

The methods employed have been detailed elsewhere. ${ }^{1} \mathrm{~A}$ total of 262 patients with idiopathic Parkinson's disease were assessed in their own homes using a questionnaire and physical examination. Five patients refused to be seen but cooperated with questions to a variable degree. No attempt was made to influence treatment before examination; we simply observed the features present for each patient at one point in time. Details included the age of patients; their duration of disease; common current symptoms known to be associated with Parkinson's disease and three control symptoms that were not; present residence; early retirement; car driving; and concomitant disease. Current symptoms were assessed by asking patients to think about the worst days of the two weeks before the visit and to answer "yes," "no," or "uncertain" about a wide range of symptoms known to be associated with Parkinson's disease. When an answer was not applicable or unknown it was also marked "uncertain." Asking about the worst days introduced bias towards higher levels of symptoms; this was done intentionally, however, $(a)$ to produce some degree of uniformity and $(b)$ to find out just how common and wide ranging symptoms were.

Drugs being used were noted, signs of the disease rated using the Webster scale, ${ }^{2}$ and an overall assessment of disability made using the rating system of Hoehn and Yahr. ${ }^{3}$ Patients were asked the identity of the doctor who regularly reviewed their disease and for details on which therapists they had seen. Who therapists were and the nature of their work were carefully explained. Whenever possible all answers were validated from hospital notes and, particularly when there was doubt, by carers or therapists also.

\section{Results}

Of the 267 patients, $222(83 \cdot 1 \%)$ were over 65 . The age range was $40-92$ years with a median of $75 \cdot 3$. A total of 204 patients $(76 \cdot 4 \%)$ were living in the community, and 51 of these $(25 \cdot 0 \%)$ lived alone. Patients had a mean of $2 \cdot 8$ 
other medical conditions encompassing the whole range of disorders found in their age group. Of the 263 patients whose drug treatment was known, 201 $(76.4 \%)$ were taking levodopa alone or in combination with an anticholinergic or bromocriptine. Ten patients $(3.8 \%)$ were taking an anticholinergic alone, two selegiline, and three amantadine. Only 47 patients (17.9\%) were not receiving drug treatment.

Twenty nine of 253 patients ( $11.5 \% ; 19$ men, 10 women $)$ claimed that they had retired early because of their disease. Age at onset was known for all 29 , and more appropriately they represented $28.4 \%$ of the 102 patients whose disease had begun before retirement age.

Of the 84 patients who had ever driven a car, $60(71 \cdot 4 \%)$ claimed to have given up driving because of their Parkinson's disease and the remainder continued to drive. Of those who had given up, most had done so on the advice of relatives, friends, or their doctor.

The duration of disease was known for 242 patients. Of these, $136(56 \cdot 2 \%)$ had had the disease for more than five years, the period by which a substantial proportion begin to experience breakthrough of their disease and complications of long term levodopa. The median duration of disease in the 242 patients was $7 \cdot 2$ years.

Table I lists the 10 most common symptoms appearing in the data obtained from 265 patients. Six of the symptoms reflected problems with mobility. In addition there was a wide range of other problems: 100 patients $(37 \cdot 7 \%)$ complained of freezing episodes, $76(28 \cdot 7 \%)$ of sweating excessively, $75(28.3 \%)$ of urinary frequency, $56(21 \cdot 1 \%)$ of urinary incontinence, $63(23.8 \%)$ of constipation, $49(18.5 \%)$ of difficulty in swallowing, 42 $(15 \cdot 8 \%)$ of unexpected falls, and $39(14 \cdot 7 \%)$ of unaccountable pain. A total of 128 patients said that they had regularly felt depressed in the two weeks before the visit.

TABLE I-Most common current symptoms in 265 patients

\begin{tabular}{|c|c|c|}
\hline Symptom & $\begin{array}{l}\text { No }(\%) \text { of patients } \\
\text { positive }\end{array}$ & $\begin{array}{l}\text { No (\%) of patients } \\
\text { uncertain }\end{array}$ \\
\hline Walking slowly & $207(78 \cdot 1)$ & $33(12 \cdot 5)$ \\
\hline Slower dressing & $207(78 \cdot 1)$ & $22(8 \cdot 3)$ \\
\hline Difficulty getting out of chair & $185(69 \cdot 8)$ & $19(7 \cdot 2)$ \\
\hline Difficulty turning in bed & $178(67 \cdot 2)$ & $32(12 \cdot 1)$ \\
\hline Shuffling & $176(66 \cdot 4)$ & $29(10.9)$ \\
\hline \multicolumn{3}{|l|}{ Stooping when walking or falling to one } \\
\hline side when sitting & $176(66 \cdot 4)$ & $24(9 \cdot 1)$ \\
\hline Speech difficulty & $172(64 \cdot 9)$ & $22(8 \cdot 3)$ \\
\hline Difficulty starting movements & $171(64 \cdot 5)$ & $22(8 \cdot 3)$ \\
\hline Handwriting change & $171(64 \cdot 5)$ & $48(18 \cdot 1)$ \\
\hline \multicolumn{3}{|l|}{ Tremor in arm: } \\
\hline Right & $145(54 \cdot 7)$ & $15(5 \cdot 7)$ \\
\hline Left & $143(54 \cdot 0)$ & $14(5 \cdot 3)$ \\
\hline \multicolumn{3}{|l|}{ Control symptoms: } \\
\hline $\begin{array}{l}\text { Pins and needles in hands or feet } \\
\text { Flashing lights before eyes }\end{array}$ & $\begin{array}{l}24(9 \cdot 1) \\
25(9 \cdot 4)\end{array}$ & $\begin{array}{l}71(26 \cdot 8) \\
65(24 \cdot 5)\end{array}$ \\
\hline Itching & $10(3 \cdot 8)$ & $59(22 \cdot 3)$ \\
\hline
\end{tabular}

Forty patients were so disabled by other medical conditions that they were excluded from analysis of the principal signs and disability. A further 11 patients were excluded because they were too ill to be examined and subsequently died. Table II shows the principal signs in 214 patients. Patients with Webster grade 1 signs had mild abnormality, those with grade 2 moderate abnormality, and those with grade 3 or 4 (in the case of speech) severe abnormality. Rigidity (191 patients; $89 \cdot 3 \%$ ), bradykinesia (183; $85.5 \%)$, and typical facies $(179 ; 83.6 \%)$ were the most common signs found. Seborrhoea (97 patients; $45 \cdot 3 \%$ ) was the least common, most patients (72; $33.6 \%$ ) having a mild abnormality with increased sweating only. A large number of patients had moderate problems with rigidity $(86 ; 40 \cdot 2 \%)$,

TABLE II-Webster ratings of principal signs in 214 patients

\begin{tabular}{lrrrc}
\hline & \multicolumn{4}{c}{ No (\%) of patients } \\
\cline { 2 - 5 } Sign & Grade 0 & Grade 1 & Grade 2 & Grades 3, 4 \\
\hline Bradykinesia & $31(14 \cdot 5)$ & $97(45 \cdot 3)$ & $75(35 \cdot 1)$ & $11(5 \cdot 1)$ \\
Rigidity & $23(10 \cdot 7)$ & $92(43 \cdot 0)$ & $86(40 \cdot 2)$ & $13(6 \cdot 1)$ \\
Posture & $62(29 \cdot 0)$ & $69(32 \cdot 2)$ & $65(30 \cdot 4)$ & $18(8 \cdot 4)$ \\
Arm swing & $58(27 \cdot 1)$ & $42(19 \cdot 6)$ & $71(33 \cdot 2)$ & $43(20 \cdot 1)$ \\
Gait & $53(24 \cdot 8)$ & $51(23 \cdot 8)$ & $26(12 \cdot 1)$ & $84(39 \cdot 3)$ \\
Facies & $35(16 \cdot 4)$ & $110(51 \cdot 4)$ & $63(29 \cdot 4)$ & $6(2 \cdot 8)$ \\
Tremor & $63(29 \cdot 4)$ & $98(45 \cdot 8)$ & $49(22 \cdot 9)$ & $4(1 \cdot 9)$ \\
Seborrhoea & $117(54 \cdot 7)$ & $72(33 \cdot 6)$ & $20(9 \cdot 3)$ & $5(2 \cdot 3)$ \\
Speech & $61(28 \cdot 5)$ & $80(37 \cdot 4)$ & $55(25 \cdot 7)$ & $6(2 \cdot 8), 12(5 \cdot 6)$ \\
\hline
\end{tabular}

bradykinesia $(75 ; 35 \cdot 1 \%)$, loss of arm swing $(71 ; 33 \cdot 2 \%)$, and posture $(65$; $30 \cdot 4 \%)$. Sixty one patients $(28 \cdot 5 \%)$ were difficult to understand and 12 $(5 \cdot 6 \%)$ very difficult to understand. The signs most often assessed as severe were abnormality of gait ( 84 patients; $39 \cdot 3 \%$ ) and loss of arm swing (43; $20 \cdot 1 \%$ ).

Of the patients whose disability was assessed by the rating system of Hoehn and Yahr, $31(14.5 \%)$ and $30(14.0 \%)$ of 214 patients were graded 1 and 2 respectively. Fifty two $(24 \cdot 3 \%)$ had grade 3 disability and $78(36 \cdot 4 \%)$ and $23(10 \cdot 7 \%)$ grades 4 and 5 disability respectively. Eleven patients could not be assessed. While $113(52 \cdot 8 \%)$ of the patients were essentially independent-that is, grades 1 plus 2 plus $3-52$ of them $(24 \cdot 3 \%)$ had mild to moderate disability. The 101 patients $(47 \cdot 2 \%)$ with grade 4 or 5 disability were noticeably or severely incapacitated.

Of 265 patients, $105(39.6 \%)$ claimed that they had had no regular medical review. Fifty six $(21 \cdot 1 \%)$ were reviewed by their general practitioner, 79 $(29 \cdot 8 \%)$ at hospital and $25(9 \cdot 4 \%)$ by both their general practitioner and the hospital. When the review of patients was compared with their level of disability (table III) $18(20.5 \%)$ of those with no review had mild to moderate disability and $44(50 \cdot 0 \%)$ were noticeably or severely incapacitated.

TABLE III-Hoehn and Yahr disability grades in 214 patients distributed by procedure for medical review

\begin{tabular}{lccc}
\hline & \multicolumn{3}{c}{ No (\%) of patients } \\
\cline { 2 - 4 } $\begin{array}{l}\text { Hoehn and Yahr } \\
\text { grade }\end{array}$ & $\begin{array}{c}\text { Reviewed in } \\
\text { hospital } \\
(\mathbf{n}=79)\end{array}$ & $\begin{array}{c}\text { Received by general } \\
\text { practitioners } \\
(\mathbf{n}=47)\end{array}$ & $\begin{array}{c}\text { Not reviewed } \\
(\mathbf{n}=88)\end{array}$ \\
\hline 1,2 & $23(29 \cdot 1)$ & $12(25 \cdot 5)$ & $26(29 \cdot 5)$ \\
3 & $19(24 \cdot 1)$ & $15(31 \cdot 9)$ & $18(20 \cdot 5)$ \\
4,5 & $37(46 \cdot 8)$ & $20(42 \cdot 6)$ & $44(50 \cdot 0)$ \\
\hline
\end{tabular}

As part of our assessment one of us (AS) asked patients which therapists they had seen and how often they saw their general practitioner. Of 227 patients assessed, $57(25 \cdot 1 \%)$ had seen an occupational therapist, 16 $(7 \cdot 0 \%)$ a physiotherapist, and only $10(4 \cdot 4 \%)$ a speech therapist. Five patients $(2 \cdot 2 \%)$ claimed to see their general practitioner weekly, $93(41 \cdot 0 \%)$ monthly, 62 $(27 \cdot 3 \%)$ every six months, $18(7 \cdot 9 \%)$ at varying intervals, and $49(21 \cdot 6 \%)$ never.

\section{Discussion}

Our results are part of a larger descriptive study of Parkinson's disease as it affected a community. There were no controls for this part of the study and we therefore make no comparative claims; rather we describe things as we found them. The symptoms recorded were those known to be associated with Parkinson's disease and are consistent with findings on examination; some, however, occur with age, and similar symptoms may occur as side effects of drugs. ${ }^{4}$ Nevertheless, they represent genuine complaints from sufferers of the disease and regardless of their precise causation are therefore relevant to the need for medical review.

In summary, most of these patients with Parkinson's disease lived in the community (one quarter alone) and were elderly. They had other medical problems as well and a lot of troublesome symptoms of complex origin, many of which are known to be associated with Parkinson's disease. There was a high prevalence of moderate to severe disability. Drugs were commonly prescribed, and over half the patients had had the disease long enough to create complex management problems. Despite this setting a substantial proportion of patients claimed not to have had regular medical review and evidently had not been seen by therapists.

How much the apparent lack of medical review was due to failure to offer follow up and how much a result of patients failing to seek follow up was not determined. None the less, in a disease where no cure can be offered it is important to support both the patient and his or her carers. That so many perceived this support to be absent is disturbing.

One of us (AWD), who has been concerned in a hospital based follow up of patients with parkinsonism since levodopa became available in 1970, finds that after the initial one or two years of treatment the need for follow up simply to adjust drugs reduces and 
may be satisfied by visits every three to six months and later yearly. In many cases this may have to be increased for a time when the initial beneficial effect of levodopa is waning. But again an equilibrium is reached where the maximum possible benefit seems to have been achieved-even if control of the disability is far from adequate. At such a point patients still like and probably benefit from fixed occasional return appointments to discuss changes in their circumstances and be directed to appropriate therapists. Increasing intellectual deterioration, whether due to the disease or simply related to increasing age, may pose extra problems in management. Some patients may be lost to follow up because of confusion over appointments.

It may be argued that follow up by the general practitioner would be more efficient because of his close contact with the patient - for example, being called in for other reasons. Nevertheless, a clinic dedicated to the follow up of patients with Parkinson's disease has definite advantages. Initial referral of suspected cases avoids the problem of patients with other disorders - for example, essential tremor-being misdiagnosed and given medication which might make the exclusion of parkinsonism more difficult subsequently. Although the disease is common in epidemiological terms, ${ }^{156}$ an average practitioner may expect to have no more than five patients with the disease on his list and is unlikely to gain sufficient experience to allow optimum care. Also new developments in the drug treatment of parkinsonism may be tested more effectively in a special clinic.

The staffing of a clinic may be from neurological, geriatric, rehabilitation, or general medical sources depending mainly on the level of interest of possible participants in different areas. Neurologists have organised and run the clinic for parkinsonism in Aberdeen, but as patients age more and more of them encounter problems which may require the help of other specialists. Such a clinic must maintain good communication with and cooperation from the general practitioner. In Scotland this is helped by the fact that hospital clinics do not supply prescriptions for drugs directly but only through the patient's general practitioner. A letter giving recommendations for these must therefore be sent after each clinic visit. A system of shared care, similar to that practised by many centres for diabetes mellitus, may be worth examining.

The small number of patients seen by therapists agrees with the findings of the Parkinson's Disease Society.' Explanations are probably multiple, not least because many doctors, certainly in the early stages, concentrate on trying to remove the signs and symptoms of the disorder by medication. Only when the effect of drug treatment is waning do they consider referral for paramedical help. At that point regular medical follow up may have been reduced, so that opportunities for considering, say, occupational therapy, may be missed. As a general rule patients should be seen for assessment by therapists sooner rather than later. Though the role of non-drug management in Parkinson's disease has been contentious, Beattie and Caird have shown the value of patients at home being assessed by an occupational therapist, receiving advice on increasing activities of daily living and obtaining appropriate aids. ${ }^{8}$ Evidence supporting the need for regular assessment was, firstly, the number of new aids found to be required at follow up and, secondly, the number of aids unused because the disease had progressed beyond their ability to help. The occupational therapist has a part to play at every stage of the disease when function is impaired so that maximum independence can be maintained.

Until recently there was a negative attitude towards speech therapy among clinicians 9 and even among therapists themselves. ${ }^{10}$ Fortunately, there are now encouraging results from work in Glasgow, which has shown benefit from proprioceptive neuromuscular facilitation ${ }^{11}$ and prosodic therapy. ${ }^{12}$ The regimens are, however, intensive and require a high degree of patient motivation. In addition, therapists can advise on voice amplification aids. There has also been increasing awareness of the speech therapist's ability to help with swallowing problems. In these circumstances possibly more than $4 \%$ of patients with Parkinson's disease should be seeing a speech therapist.

Though many physicians and physiotherapists believe that they are helping patients with physiotherapy, attempts to provide objective evidence have resulted in conflicting opinions. Gibberd et al, who studied patients with stable disease, could show no benefit from therapy performed twice a week for four weeks in an outpatient department. ${ }^{13}$ Their results were challenged by Andrews, ${ }^{14}$ Steiner and Flewitt, ${ }^{15}$ and Franklyn $e t$ al, ${ }^{16}$ the latter finding definite improvement in their own similarly controlled trial. Only a total of 45 patients were included in these controlled trials. Though patients with stable disease may show no benefit, the underlying trend of the disease is one of inexorable decline. Longer trials with more patients may show that physiotherapy slows this decline and is of benefit. The Physiotherapy Advisory Group of the Parkinson's Disease Society has produced a standardised assessment form, which should provide a useful tool for further studies. Unfortunately, there is no agreement on the most appropriate method of treatment, and indeed there is growing suspicion that regular guided exercise aimed at all round fitness and mobility may be as relevant as any particular physiotherapy method. Patients can benefit from this guidance at any stage of their disease, though they are unlikely to seek it until they begin to experience difficulty with mobility.

Long term multicentre controlled studies are necessary to evaluate the most appropriate and cost effective ways to use the skills of all therapists (who are themselves in short supply ${ }^{17}$ ) to benefit and improve the quality of life of patients with Parkinson's disease.

We are grateful to all doctors in Aberdeen who referred patients for this study and to the patients themselves. Valuable help was given by $\mathrm{Dr} J$ Gordon Paterson, Miss Ianthe Dingwall-Fordyce, Mrs S Muir, and Ms Maureen Hughes (Dundee). We are grateful for the constructive advice of Dr W J MacLennan (Dundee). Funding was given by Grampian Health Board Endowment Funds and Roche Products.

\section{References}

Mutch WJ, Dingwall-Fordyce I, Downie AW, Paterson JG, Roy SK. Parkinson's disease in a Scottish city Br Med 7 1986;292:534-6.

2 Webster DD. Critical analysis of the disability in Parkinson's disease. Modern Treatment 1968;5:257-82.

3 Hoehn MH, Yahr MD. Parkinsonism: onset, progression and mortality. Neurology (Minneap) 1967;17:427-42.

4 Bulpitt CJ, Shaw K, Clifton P, Stern G, Davies JB, Reid JL. The symptoms of patients treated for Parkinson's disease. Clin Neuropharmacol 1985;8:175-8.

5 Sutcliffe RLG, Prior R, Mawby B, McQuillan WJ. Parkinson's disease in the district of the Northampton Health Authority, United Kingdom. A study of prevalence and disability. Acta Neurol Scand 1985;72:363-79.

6 Gudmundsson KRA. A clinical survey of parkinsonism in Iceland. Acta Neurol Scand 1967; 43(suppl 33):9-61.

Oxtoby M. Parkinson's disease patients and their sacial needs. London: Parkinson's Disease Saciety, 1982 .

8 Beattie A, Caird FI. The occupational therapist and the patient with Parkinson's disease. Br Med $\mathcal{J}$ $1980 ; 280: 1354-5$

9 Pearce JMS. Drug treatment in Parkinson's disease. Br Med $\mathcal{f}$ 1984;288:1777-8.

10 Greene MLC. The voice and its disorders. London: Pitman Medical, 1980:298-327.

1 Scott S, Caird FI. Speech therapy for patients with Parkinson's disease. Br Med f 1981;283:1088. Scott S, Caird FI. Speech therapy for Parkinson's disease. $\mathcal{f}$ Neurol Neurosurg Psychiatry $1983 ; 46: 140-4$

13 Gibberd FB, Page NGR, Spencer KM, Kinnear E, Hawksworth JB. Controlled trial of physiotherapy and occupational therapy for Parkinson's disease. Br Med f 1981;282:1196.

14 Andrews K. Controlled trial physiotherapy and occupational therapy for Parkinson's disease. BrMed f 1981;282:1475.

15 Steiner T, Flewitt B. Controlled trial of physiotherapy and occupational therapy for Parkinson's disease. $\mathrm{Br} \mathrm{Med} \mathrm{F} \mathrm{1981;282:1970.}$

16 Franklyn S, Cohout LJ, Stern GM, Dunning M. In: Rose FC, Capildeo R, eds. Research progress in Parkinson's disease. Tunbridge Wells: Pitman Medical, 1981:397-400.

17 Andrews K, Brocklehurst JC. Provision of remedial therapists in geriatric medicine. $\mathrm{Br} \mathrm{Med} 7$ 1984;289:661.

(Accepted II fuly 1986)

\section{Correction}

The acquired immune deficiency syndrome and epidemic of infection with human immunodeficiency virus: costs of care and prevention in an inner London district

We regret that two errors occurred in this article by Dr Anne $M$ Johnson and others (23 August, p 489). In section B of the table the cost for ward adaptation should have read $£ 200000$, not $£ 15000$, and in the section on total costs in the text the capital cost should have read $£ 472000$, not $£ 287000$. 